\title{
Climate Change in India: A Wakeup Call from Bollywood
}

\author{
Manvi Sharma ${ }^{1}$ \& Ajay K. Chaubey ${ }^{2}$ \\ ${ }^{1}$ Research Scholar(English, National Institute of Technology, Uttarakhand, E-mail- \\ manvi.sharma4779@gmail.com, ORCID ID oooo-0003-2708-4403 \\ ${ }^{2}$ Assistant Professor-I (English, National Institute of Technology Uttarakhand, E-mail- \\ kcajay79@nituk.ac.in, ORCID ID oooo-ooo2-6413-798
}

\begin{abstract}
Amidst Bollywood's romanticized landscapes and grandeur settings, depiction of the flora and fauna, roaring rivers and drought prone lands, is difficult to locate. But the new millennium has witnessed some new generation filmmakers, sensitized towards the ecological concerns, thus marking a shift from the illustration of idealised landscapes to the representation of nature's wrath. Since, cinema in India, has a deep-rooted impact on the masses, these creators employ films as tools to sensitize the population towards the climate change threat which though as perilous as the COVID-19 crisis, is often ignored by a significant amount of population. Dawning upon themselves the responsibility of environmental awakening, Nila Madhab Panda and Abhishek Kapoor highlight in their movies, Kadvi Hawa(2017) and Kedarnath(2018), respectively, the horrors of human callousness, leading to drastic change in Climatic condition in India. Panda's Kadavi Hawa, dealing with non-repayment of loans followed by suicides, portrays the heartwrenching imagery of environmental degradation and Climate change that has rendered the Village of Mahua, arid and infertile. Kapoor's Kedarnath on the other hand, appeals for action through horrifying imagery of the catastrophic floods that disrupted the holy town of Kedarnath, in 2013. Through a detailed analysis of the aforementioned visual portrayals, this article aims to emphasise as to how Films can play an important role in effectively addressing dealing with the issues related to Climate. Further, the rationale of this paper is to underscore the possibility of more such storylines, as a tool towards effective engagement and levitation of conscience.
\end{abstract}

Keywords: Climate Change, Cultural Studies, Bollywood, Films, Eco-criticism etc

\section{Introduction}

From overpoweringly protesting on the streets, to posting outrage on Social media, India has over the years, evolved to be a Nation, where citizens express their resentment even more vociferously. But, amidst numerous issues being voiced through television debates, and trending hash tags, what has struggled to find its place, is the Climate Change threat that looms large upon us.

Over the last 150 years, significant changes in Climate change have been recorded, which are markedly different from the last at least 2,00o years. These changes include a $0.85^{\circ} \mathrm{C}$ increase in average global temperatures, sea-level rise of over $20 \mathrm{~cm}$, significant shifts in the seasonality and intensities of precipitation, changing weather patterns and significant retreat of nearly all continental glaciers. (Maslin, 2014, pp. 44-45)

(C) AesthetixMS 2020. This Open Access article is published under a Creative Commons Attribution Non-Commercial 4.0 International License (http://creativecommons.org/licenses/by-nc/4.o/), which permits non-commercial re-use, distribution, and reproduction in any medium, provided the original work is properly cited. For citation use the DOI. For commercial re-use, please contact editor@rupkatha.com. 
In spite of such menacing figures, there exists, nonetheless, a state of unresponsiveness, about the climate change catastrophe, across the World and especially in the Indian Sub-continent, where cyclones, storms, floods and droughts are common natural hazards. Starting from the Bhuj earthquake in 2001, Heat Wave in April 2002, The Tsunami of 26th December 2004, Maharashtra Floods July 2005, massive 2010 Storm in Eastern India, and 2013 Uttarakhand Floods, India, over the last decade, has witnessed massive disasters resulting in death, destruction and economic damage. Unfortunately, these catastrophes have not been able to drive people out of their deep slumber and there exists, a general indifference, opines Ghosh (2016) in the following words:

Despite the fact that India has innumerable environmental organisations and grassroots movements...The voices of the country's many eminent climate scientists, environmental activists, and reporters do not appear to have made much of a mark either. (p. 169)

What exactly is the reason? Is it because the scientific and methodical Jargon of the Research, debates and activism on Climate Change crisis, has failed to imprison the attention of the masses? And if so, what particular approaches, can be used as tools to make the inhabitants of this planet apprehend the intensity of the Climate change threat upon them as well as other co-existing species?

While probing for tools to raise the conscience of the general masses, the buck unquestionably stops at Popular Culture, which can literally be defined as "mass culture"(Storey, 2009, p. 8) or "any Cultural product that has a mass audience"(Zeisler, 2008, p. 1 ). Aimed at large audiences and portraying the sentiment of the masses, the artefacts of the Popular Culture-cinema, television shows, fiction and even social media, can be utilised for dissemination of awakening programmes among masses all across the world to "provide deep insights into the concerns, anxieties and desires of their times" (Jones et al., 2011, p. 3).

But, in what ways and to what effect can popular culture serve as medium to tackle the Climate Change crisis? In order to answer the aforementioned question, it is essential to take into consideration the fact that one of the Popular Culture mediums; films, have a deep-rooted impact on the commonalities and a significant amount of the World's population derives its knowledge about contemporary issues through them. From highlighting their desires to shaping their ideologies, commercial and well as non-commercial films possess the merits to influence the ideas, values, beliefs, action and most essentially, the reaction of its viewers. In such a scenario, Films can indisputably be used as tools to sensitize the population towards the climate change threat which is as perilous as the current COVID-19 crises.

In recent years, much attention is being paid to the films dealing with Environment and Environmental Crisis, all across the Globe with Hollywood films and Documentaries like An Before the Flood (2016), Warcraft (2016), An Inconvenient Sequel: Truth to Power (2017) and others, that have garnered accolades for their remarkable visuals and presentation of environmental issues that require urgent human attention. These popular representations of Environmental concerns in Cinema, have paved a way for the new paradigm of Eco-cinema studies. The term Eco-cinema, whose coinage and first usage can be attributed to Roger C. Anderson's 'Ecocinema: A Plan for Preserving Nature'(Chu, 2016, p. 11), encompasses Cinema produced with a vision to bring the environmental issues to the forefront, aiming to deal with human disengagement with nature and its concerns that require urgent attention. Ingram (2013) defines Eco-film as a

film that has a conceptual content which more or less explicitly promotes ecological ideas, or, more generally, an ecological sensibility. This conceptual content is usually understood 
to heighten viewers' awareness of concepts such as ecocentrism and ecological interconnectedness. (p. 44)

In other words, Eco-cinema can be termed as a tool that helps bring to the forefront, issues related to nature and its resources. Not only do these movies explore the relationship between nature and humans, but also serve as visual warnings regarding the impending doom due to Global warming, Climate change, and other ecological hazards like water contamination, and air toxicity due to the increasing pollution levels, across the Globe. While tracing its history, it is evident that this newly instituted genre of Ecocinema has burgeoned out of Ecocriticism in the past one decade. Defined as the study of the relationship between nature and Literature,

Ecocriticism takes as its subject, the interconnections between nature and culture, specifically the cultural artefacts of language and literature. (Glotfelty, 1996)

Thus, Ecocriticism can be understood as a mode of analyses that propounds that Culture and Nature work hand in hand with each other, shaping and being shaped by each other simultaneously. Through a detailed analysis of Cultural artefacts, (films in case of the trajectory of Ecocinema) Ecocritics, investigate--1) their potential to draw the readers' attention towards the issues of the environment, 2) their usefulness as tools to generate ecological consciousness and 3) their ability to bring about a reaction to the Ecological crisis.

But how far has Ecocriticism influenced Cinema in India? Are there any films made or being made to trigger off the Ecological awakening of the audience? Amidst their romanticised landscapes, larger than life settings, sartorial splendour, and sleazy item numbers, do Bollywood films incorporate the horrifying imagery of the roaring rivers, drought prone lands, and barren ice lands? An answer to these questions, a decade ago, certainly would have been negative. But with the turn of the century, some new generation filmmakers, like Nila Madhab Panda, Abhishek Kapoor, Mike Pandey and others have found themselves sensitized towards the environmental concerns, and have marked a shift from the illustration of idealised romantic landscapes to the representation of nature's sound and fury. What sets these movies apart from the conventional Bollywood films is their utter reluctance to use nature as a decorative background to romantic songs but instead placing it at the centre to highlight the human ignorance and greed that leads to an unstable Ecological environment.

Through a detailed analysis of Nila Madhab Panda's Kadvi Hawa (2017) and Abhishek Kapoor's Kedarnath (2018), we attempt to emphasise that Popular Culture, particularly Films, can play an important role in effectively addressing the issues related to Climate Crisis. Through an in-depth analysis of the scenes and dialogues, it can be established that Eco-films can act as an urgent appeal to deal with the horrors of human callousness, leading to drastic change in Climatic conditions in the Indian sub-continent. An exploration of the representation of human-nature relationship in the afore-mentioned films can be a saga of human unresponsiveness, which has brought upon the Globe, a drastic change in Climatic Conditions. Further, the rationale of this paper is to identify the elements that these film-makers have incorporated in their storylines and visuals to bring about a change in the audiences' reaction, thus stressing upon the possibility of more such storylines, as a tool towards effective engagement and conscience raising.

\section{Kadvi Hawa}

Padma Shri Award Winning director, Nila Madhabh Panda's efforts to contribute towards the issues related to Environment and Ecology, unearth themselves through his critically acclaimed films and documentaries, which represent a true picture of the "socio-environmental" crisis in India. Both his eco- narratives, Kaun Kitney Pani Mein (2015) and Kadvi Hawa (2017) are hailed as 
Hindi Film Industry's major contributions to the genre of Ecocinema. While Kaun Kitney Paani mein is a satirical take on the sensitive issue of water scarcity in contemporary India, Kadavi Hawa, is an endeavour to delve deep into human conscience, bringing the audiences into reflecting upon their contribution towards bringing the Anthropocene.

Set in drought-stricken, north-Indian fictional village of Mahua, Kadavi Hawa, revolves around a sightless father, Hedu, (Sanjay Mishra), attempting to save his debt-ridden, farmer- son Mukund, (Bhupesh Singh), from the clutches of the "suicide-disease" that has gripped the village. In an attempt to clear off his Mukund's debts, Hedu strikes a deal with the merciless loan recovery agent Gunnu Babu, (Ranvir Shorey). In exchange for the information about farmers 'wages, needed to coerce them to repay their loans, Hedu demands for a clearance of a loan of 42,580 rupees that haunts his son's life. Wrapped under the narrative agricultural crisis and farmers' suicides in India, the film is a pungent representation of the reality of Global Warming and Climate Change in India, leading to natural resource depletion and Environment degradation. It is indeed human callousness that has rendered the village of Mahua and many others villages, arid. As the Greenhouse gasses emissions increase, there is an increase in the overall temperatures, resulting in a permanent change in Climatic Conditions of a region. Rainfall in such regions becomes episodic, and an insufficient amount of water supply, "whether surface or underground water" (Maslin, 2014, p. 80), leads to an agricultural crisis. As "droughts have a substantial impact on the local ecosystem and agriculture, including drops in crop growth and yield and loss of livestock" (Maslin, 2014, p. 81), farmers rely on loans to survive, in anticipation of the rainfall to help them yield crop and repay the loans. This anticipation however, never ceases to exist and ignored by the government, chased by the loan recovery agents like Gunnu Babu aka "Yamaraj", farmers like Mukund, and many others, succumb to the "suicide-disease" that plagues their village.

Kadvi Hawa qualifies to be termed as a powerful and engaging contribution to the genre of Ecocinema. As Paula Willoquet-Maricondi (2010) opines,

Ecocinema overtly strives to inspire personal and political action on the part of viewers, stimulating our thinking so as to bring about concrete changes in the choices we make, daily and in the long run, as individuals and as societies, locally and globally. (p. 45)

Kadavi Hawa, by the same token, places nature at the centre of the narrative. Through the catastrophic visual imagery of dearth and drought encoded in its scenes, the movie consciously drifts the audiences into a realisation of a sudden need for action. As sightless Hedu walks with a stick to pave way for himself through the parched land, with not even a spot of greenery and a drop of water around, it is the our own "Ecological Blindness" that the filmmaker exposes. The dried, depressed landscape invokes a sense of urgency in our realisation and action towards Global Warming. This urgency is in fact the need of the hour as,

No less than 24 per cent of India's Arable land is slowly turning into desert, and a 2-degree Celsius rise in global average temperature would reduce the country's food supply by a quarter. (Ghosh, 2016 p. 120)

With increasing Global temperatures, the natural resources of water; rivers and water bodies, are drying up, simultaneously increasing the load on accessible water resources; wells and tube wells, which in turn are exhausted. The need to procure fresh drinking water thus forces the farmers' wives like Hedu's daughter-in-law, Parvati (TillotamaShome), to fetch drinking water from areas at a larger walking distance from the village to store it in bottles and earthen pots. Hedu's repeated commands to his granddaughter Kuhu not to fill up the whole bottle every time 
he asks for water for defecation purposes, is in fact, a stern warning call to the human population to use the natural resources judiciously and to conserve them before they deplete. Kuhu's statement "Where would you get water from?" (Translation ours), in response to Hedu's commands is an echo of the warning that Amitav Ghosh issues in his landmark work, The Great Derangement (2016):

The rivers that Sustain South and South-East Asia rise in Tibet and the Himalayas; the waters that are stored there, in the form of accumulations of ice, sustain 47 per cent of the world's population...But this region is warming twice as fast as the average global rate, and in 2008 it was found that the Himalayan glaciers has already lost all the ice formed since the mid 1940s; by some reckonings, one-third of them will disappear by 2050. (p. 121)

Moreover, the visual of Hedu drinking water from a plastic packet, while on his trip to the Bank is a frightening representation of the impending dystopian future, an age of "The Great Derangement" (Ghosh, 2016) brought about by human interference with nature, with no natural resources left for human use.

The disastrous impact of Climate Change on the Cycle of seasons is highlighted by the filmmaker through a classroom dialogue between Kuhu's classmate and the teacher. While the teacher constantly chants that there are four seasons in a year, the boy from "Beehad Mahua" is left spellbound at the claim, as summer and winter are the only seasons he knows of. His classmates' and teachers' claims of Rainfall being a full season appear absurd to him as in Beehad Mahua, "it only rains two or three a year, occasionally sometimes in winters and sometimes in summer"( translation ours). It is Hedu, who can sense the devastating effect of Climate Change upon the air, the air according to him smells pungent and is perpetually dry. On being narrated the classroom incident by Kuhu, a distressed Hedu responds, "there used to be four seasons...Air brings clouds and seasons, the fragrance tells that something is wrong with air, it has fallen sick." (Translation ours)

With greenhouse gas emission rapidly rising in the cities, it is the poor strata that bear the brunt. It is the marginalised section of the society that pays the price of luxurious, carbon- based lifestyle that the Rich maintain. Erle C. Ellis (2018) mentions;

Wealthy people use vastly more energy and emit far more carbon dioxide than the poor. Travelling by personal car and jet aeroplane, which most people on Earth have never done, are some of the most energy intensive things a human can do. (p. 133)

As the Greenhouse emissions increase, the mercury soars, leaving the earth parched and disrobed of its natural greenery. Hedu's "office"- his meeting spot with Gunnu Babu, which he frequently visits with his buffalo Annapurna and a water bottle, appears to be the only shady spot in the village. Deprived of colour, the village seems dejected, as if desperately begging for mercy from the Death God Gunnu Babu and the Rain gods. While the earth's desperation for rain is depicted through Ramanuj Dutta's exemplary cinematography, depicting brown, barren, thirsty and dusty landscape, a farmers' plight and anticipation for rainfall is presented through Hedu's words, "You are like rainfall in my life" (translation ours) which he utters to Gunnu Babu as he transfers a portion of the profit that he has earned using the information provided by Hedu.

What is graver is the fact that the lack of education renders the farmers unable to cope up with the repercussions of the Climate change. With increasing temperatures, the agricultural productivity decreases, and as the farmers have no knowledge of the resources to vary the planting time or so switch to a different crop, the land becomes permanently barren waiting for the rainfall. This Climate Change induced infertility is deftly cinematized as the screen features no 
sign of vegetation in "Beehad Mahua", apart from some trees which are only functional to make teeth cleaning twigs. Onions and Potatoes are the only vegetables that Parvati cooks in her kitchen.

Feared among the farmers as "Yamraj", Gunnu Babu at first appears to be a wicked, loanrecovery agent. But as Gunnu's story unveils itself, it is clear that it's not Gunnu, who is the real villain; it's collectively human populace, who is causing havoc on the Planet Earth. Hailing from Odhisa, he himself, is a victim of nature's wrath in the form of Cyclones that frequently hit his hometown Kendrapara. Having lost his father in a cyclone that caused devastation in Odhisa, he is forced to relocate to Mahua, in order to provide for his family- his mother, wife and two daughters, and to bring them to Beehad Mahua- a much "safer place" for someone who has seen destruction and Catastrophe that water and Rains can cause.

The grim and hopeless ending for both Hedu and Gunnu serves as a reminder of an impending doom to the masses. The wailful ending where Hedu loses Mukund to suicide plague, and Gunnu loses his family in the cyclone $6 \mathrm{~B}$ is reflection of our own future- an age of complete loss and chaos, from where there is no return is possible.

\section{Kedarnath}

In the records of the Climate Change History, year 2013, has been calamitous for India especially for the State of Uttarakhand, where heavens poured devastation on the holy town of Kedarnath, eventually leading to the worst flood to hit India in a decade. 144 bridges collapsed, 400 villages were washed away, and 1636 roads were damaged, sweeping with them, over 15000 thousand villagers and pilgrims and 5000 animals (Das, 2013). While the data seems gruesome, what is more horrible is the fact that the disaster, though termed as a "natural calamity", was actually brought upon the holy town through human induced catastrophe: Global Warming. There can be two reasons as to how Climate Change caused this destruction; 1) "A Warmer Climate means air can hold more water and more water vapour, so the monsoon winds carry more moisture"( Maslin, 2014, p. 77), causing sudden deathly outpour. 2) In a warmer Climate, there is a rapid expansion of the Glacial lakes, "and their sudden outbursts releases billions of cubic meters of water ending in catastrophe" (Das, 2013). Chorabari glacier, pitched over Kedarnath, destabilized by heavy downpour, released "flood water carrying huge load of sludge, debris and boulders" (Das, 2013) inflicting death and devastation.

Skilfully weaving this 2013 calamity with the narrative of two inter-faith Lovers-Mandakini aka Mukku (Sara Ali Khan), a Hindu Priest's daughter and Mansoor (Sushant Singh Rajput), a Muslim Human Porter-Abhishek Kapoor's Kedarnath, is a moving representation of human greed and mismanagement that wreaked havoc on the holy town in 2013. Centred on the disaster and human actions that led to it, Kedarnath qualifies to be included in the genre of Ecocinema as

In addition to natural phenomena, ecocinema also concerns human-induced problems on ecology and the environment. Industrialization, urbanization and overdevelopment signal the realization of negative consequences in the forms of environmental degradations (Chu, 2016).

This human avarice is brought to the fore-front through Kullu (Nishant Dahiya), the priest's prospective son-in-law, who in order to gain profit and meet the demands of growing number of pilgrims, plans an unlawful and haphazard construction of a two-star hotel and a Lodge at Rambada. Kullu's materialism lends him indifferent to the head priest's warning that "such construction would change the course of the river, which can be fatal." (Translation ours) 
Every year, Kedarnath receives an exodus of pilgrims who arrive to offer prayers to Lord Shiva an attain 'Moksha'. The cost of this spiritual attainment is the environmental degradation through construction of roads, bridges, lodges and hotels, in order to accommodate the pilgrims and boost business. As Beth Berilla (2010) opines

Environmental justice is best fulfilled when humans position themselves in a dynamic and mutually interdependent relationship with nature. (p. 117)

Mansoor's proposal to "put a limit to the number of pilgrims instead of carrying out the construction" is thus, an attempt to maintain a cordial relationship between the human and the non-human. The porter community's reluctance to the blind urbanization in the valley serves as an eye-opener for 1) the authorities who grant permission for such irresponsible construction, 2) the pilgrims who fail to place nature's call for peace above their self-interests, and 3) residents who tend to forget that that the valley does not belong to them, but it's the valley that nurtures them.

It is not only Mansoor who is anxious about the degradation that the valley is witnessing; his love interest Mandakini is equally distraught with the ecological deterioration of the natural resources: particularly infuriated with the hoardings and billboards "which cover the valley instead of its rightful owners; flowers and greenery". Mandakini, who acquires her name from the river Mandakini that originates from the Chorabari glacier, is in fact, depicted as the latter's human representation. It is through her, Kapoor makes the river speak, as if delivering a forewarning to stop changing her course as "she can eat up the sky" and wreak destruction. Their demands unattended, and cries unheard, both the river and the girl, take it upon themselves to seek justice: While the lovelorn Mandakini prays for a curse to befall the village that forbids her union with Mansoor, the river standing true to its repeated warnings, washes the entire town ashore.

Emotionally charging the audiences through the weaving the real footage of the tragedy, with animations, the director indisputably increases the level of concern towards Nature in the viewers. The brilliant yet dreadful picturization of deathly rain and flood-engulfing thousands of pilgrims, villages, animals, bridges, roads and buildings with them-induce fear in minds of the audiences, shaking them out of their "denial" and bringing a sense of urgency towards Climate Crisis that grips the earth.

\section{Conclusion}

We live in an age, where, human intervention with the course of nature has caused environmental degradation to an extent that with each passing day, the earth seems more damaged than ever before. This devastation is clearly visible through a drastic change in the climatic conditions, all over the planet, leading to droughts, floods, cyclones and storms. However, the alarming records of these calamities have still not been able to attract the attention of the general masses, which live in a state of constant denial, unwilling to bring changes to their lifestyle and decrease their carbon foot-print. Therefore, in such a scenario, popular culture works, especially cinema, can emerge as "saviours of the earth", owing to their mass outreach-which can prove to be useful to disseminate knowledge about the Climate Change threat that looms upon us. Dawning upon their shoulders, the responsibility of awakening the "ecological conscience" of the audiences, a few new-generation film-makers have greatly contributed towards the genre of Ecocinema through movies such as Kadvi Hawa and Kedarnath which raise concern towards human intervention that has led to a drastic change in temperature. Unlike mainstream Bollywood cinema, these masterpieces place nature at the centre of their narratives to highlight the human recklessness 
that has paved a way for calamities and natural disasters. Located at two polar opposite locationsa drought prone and a flood prone area-the connecting strand between both the narratives is the human greed that has wreaked havoc. Interestingly, to call for rapid action, both the creators employ visuals and dialogues as mediums; Whereas, the employment of catastrophe imagery coupled with the crippling aftermath of the calamity, generates concern as well as fear in the minds of the viewers, the films' dialogues, voice the worries of the Anthropocene and impart motivation to the viewers to work together to conserve the natural resources before they deplete. Intricately weaving fiction and facts together, the directors, break away from the categorical divisions of "The Critical" and "The Commercial", and weave interdisciplinary storylines that are entertaining as well as 'conscience raising', thus enhancing scope and possibility of more such narratives. Further, both the narratives induce thoughtfulness, motivate the viewers to gain agency, and call for urgent action.

\section{Acknowledgement}

The publication of this paper was possible through immense support and Institutional Research Fellowship from National Institute of Technology Uttarakhand.

\section{References}

Anderson, R. C. (1975). Reflections: Ecocinema: A Plan for Preserving Nature. BioScience, 25(7), 452-452. doi: 10.1093/bioscience/25.7.452

Berilla, B. (2010). Engaging the Land/Positioning the Spectator: Environmental Justice Documentaries and Robert Redford's The Horse Whisperer and A River Runs through it. In P. Willoquet-Maricondi (Ed.), Explorations in Ecocriticism and Film (pp. 116-133). Virginia: University of Virginia Press.

Bulfin, A. (2017). Popular culture and the "new human condition": Catastrophe narratives and climate change. Global and Planetary Change, 156, 140-146. doi:10.1016/j.gloplacha.2017.03.002

Chatterjee, S. (2017, November 23). Kadvi Hawa Movie Review: Ranvir Shorey Matches Incredibly Impactful Sanjay Mishra. Retrieved August 29, 2020, from https://www.ndtv.com/entertainment/kadvi-hawamovie-review-ranvir-shorey-matches-incredibly-impactful-sanjay-mishra-1779050

Chu, K. (2016). Ecocinema. Journal of Chinese Cinemas, 1o(1), 11-14. doi:10.1080/17508061.2016.1142728

Das, S. (2013). Uttarakhand Tragedy. Journal of the Geological Society of India, 82(2), 201-201. doi:10.1007/s12594-013-0141-4

Ellis, E. C. (2018). Anthropocene: A very Short Introduction. Oxford: Oxford University Press.

Garrard, G. (2012). Teaching Ecocriticism and Green Cultural Studies. London: Palgrave Macmillan UK.

Ghosh, A. (2016). The Great Derangement: Climate Change and the Unthinkable. Penguin Books India.

Glotfelty, C., \& Fromm, H. (Eds.). (1996). The Ecocriticism Reader: Landmarks in Literary Ecology. Athens, Georgia: Univ. of Georgia Press.

Goodbody, A. (2007). Nature, technology and cultural change in twentieth-century German literature: The Challenge of Ecocriticism. Basingstoke: Palgrave Macmillan.

Grossman, D. (2015, June 23). Unnatural Disaster: How Climate Helped Cause India's Big Flood. Retrieved August 29, 2020, from https://e36o.yale.edu/features/unnatural_disaster_how_global_warming_helped_cause_indias_catast rophic_flood 
Here is what happened in Kedarnath, and rest of Uttarakhand, in 2013. (2018, December 07). The Indian Express. Retrieved August 28, 2020, from https://indianexpress.com/article/research/here-is-whathappened-in-kedarnath-and-rest-of-uttarakhand-in-2013-5482050/

Howell, R. A. (2011). Lights, camera ... action? Altered attitudes and behaviour in response to the climate change film The Age of Stupid. Global Environmental Change, 21(1), 177-187. doi:10.1016/j.gloenvcha.2010.09.004

Ingram, D. (2013). The aesthetics and ethics of eco-criticism. In S. Cubitt, S. Rust \& S. Monani (Eds.), Ecocinema Theory and Practice (pp. 43-61). New York, NY: Routledge.

Ivakhiv, A. J. (2013). Ecologies of the moving image: Cinema, Affect, Nature. Waterloo, Ontario: Wilfrid Laurier University Press.

Jones, D., McCarthy, E., \& Murphy, B. (Eds.). (2011). It came from the 1950s! Popular Culture, Popular Anxieties. Palgrave Macmillan.

Kapoor, A. (Director). (2018). Kedarnath [Video file]. Retrieved August 29, 2020, from https://www.zee5.com/movies/details/kedarnath/o-o-27132

Lewis, S. L., \& Maslin, M. (2018). The human planet: How we created the anthropocene. London: Pelican, an imprint of Penguin Books.

Maslin, M. (2014). Climate change: A very short introduction. New York: Oxford University Press.

Moezzi, M., Janda, K. B., \& Rotmann, S. (2017). Using stories, narratives, and storytelling in energy and climate change research. Energy Research E Social Science, 31, 1-10. doi:10.1016/j.erss.2017.06.034

Panda, N. M. (Director). (2017). Kadvi Hawa [Video file]. Retrieved August 29, 2020, from https://www.zee5.com/movies/details/kadvi-hawa/o-o-25979

Upton, J. (2014, October 01). Climate Change's Role in Indian Pilgrim Deaths. Retrieved August 29, 2020, from https://www.climatecentral.org/news/climate-changes-india-floods-18116

Willoquet-Maricondi, P. (2010). Shifting Paradigms: From Environmentalist Films to Ecocinema. In P. Willoquet-Maricondi (Ed.), Framing the World: Explorations in Ecocriticism and Film (pp. 43-61). University of Virginia Press.

Zeisler, A. (2008). Feminism and Pop Culture. Berkeley, CA: Seal Press. 